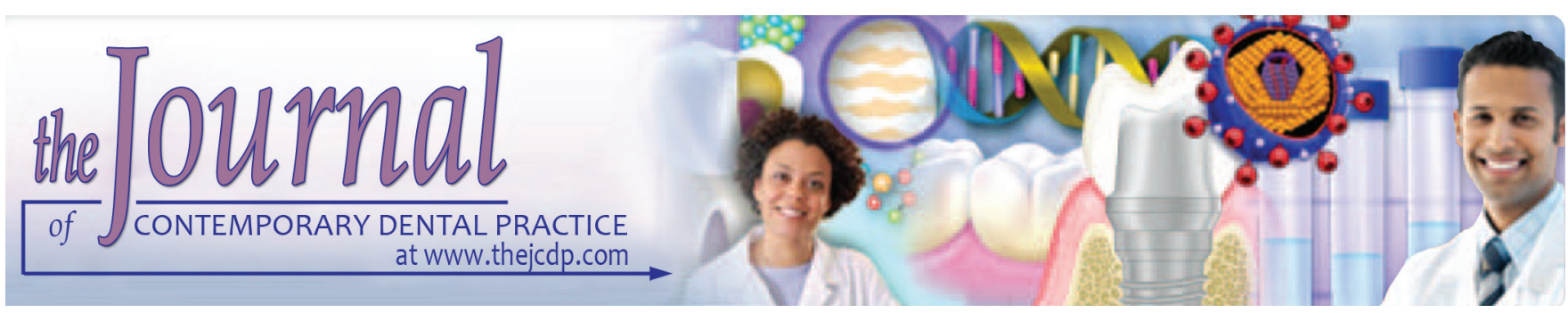

\title{
Impact of Polishing Systems on the Surface Roughness and Microhardness of Nanocomposites
}

\author{
Yasser Alfawaz
}

\begin{abstract}
Aim: The aim of this article is to evaluate the influence of finishing and polishing techniques on the surface roughness and microhardness of two composite resins with two different types of polishing systems.
\end{abstract}

Materials and methods: A total of 30 disk-shaped specimens of nanocomposite Filtek ${ }^{\mathrm{TM}} \mathrm{Z} 350$ and Ceram- $\mathrm{X}^{\circledR}$ were prepared. They were divided into three groups. The control group $(n=10)$ received no finishing and polishing. The remaining specimens were divided into two groups, and they received polishing and finishing either with PoGo or Sof-Lex system. After the polishing procedures, average surface roughness $(\mathrm{Ra})$ was assessed with a surface profilometer. The microhardness was determined using a Vickers hardness test. The data were tabulated and analyzed.

Results: The smoothest surfaces were noticed with the control group (Mylar strips) in both composite materials tested. The PoGo one-step polishing system showed significantly better surface roughness compared with the Sof-Lex polishing system. The microhardness did not show any significant variations after finishing and polishing.

Conclusion: It can be concluded that the use of $\mathrm{PoGo}{ }^{\circledR}$ onestep polishing system resulted in smoother surface with both composite materials studied compared with the Sof-Lex system. The finishing and polishing system had little influence on the surface microhardness.

Clinical significance: The finishing procedure and polishing system can affect the physical properties and performance of resin composites.

Keywords: Finishing, Nanocomposite, Polishing, Resin composite, Surface microhardness, Surface roughness.

How to cite this article: Alfawaz Y. Impact of Polishing Systems on the Surface Roughness and Microhardness of Nanocomposites. J Contemp Dent Pract 2017;18(8):647-651.

Department of Restorative Dental Sciences, College of Dentistry King Saud University, Riyadh, Kingdom of Saudi Arabia

Corresponding Author: Yasser Alfawaz, Department of Restorative Dental Sciences, College of Dentistry, King Saud University, Riyadh, Kingdom of Saudi Arabia, e-mail: yasseralfawaz@gmail.com

\section{Source of support: Nil}

Conflict of interest: None

\section{INTRODUCTION}

Optimal finishing and polishing of resin composites are prerequisites for maintaining esthetics and enhanced longevity of resin-based restorations. Smooth and polished restorations are less susceptible to plaque accumulation and extrinsic stains. ${ }^{1-3}$ It may also influence the mechanical properties of the restorations, wear resistance, and the marginal integrity of the restorations. ${ }^{4,5}$ Composite resins are widely used for the direct restoration of both anterior and posterior teeth. The surface roughness and microhardness are properties of a composite that are related to the material's resistance to masticatory forces and its appearance which influence the longevity of the restoration. $^{6}$

Nanotechnology has contributed significant advances to the resin composites. These novel resin composites, which contain nanoparticles, have improved filler technology and modified organic matrixes, which help to achieve higher degrees of polymerization. ${ }^{7-9}$ The surface roughness of a resin-composite restoration depends on several factors including filler content, size, shape, interparticle spacing, monomer type, degree of cure, and efficient filler matrix bonding. ${ }^{10}$ The nanoparticle-based filler materials also improved the surface roughness of the new generation of composite resins. ${ }^{11,12}$

Proper finishing and polishing of the composite resin restorations are important steps that enhance both the esthetics and longevity. Hence, it is imperative that efforts should be directed to improve surface smoothness for optimum results. Several studies have identified the best abrasive system, which could achieve the smoothest surface for the commercially available composites. ${ }^{13-15} \mathrm{It}$ was shown that that the smoothest surface of a restoration 
was attained when the resin was polymerized against an appropriate matrix strip. ${ }^{10,11,16,17}$ A variety of finishing and polishing procedures are commonly used for surface finishing of tooth-colored restorative materials, such as carbide burs and diamond points, abrasive disks, abrasive finishing strips, and polishing pastes. ${ }^{18}$ The resin-based composite restorations are polished with a set of highly flexible, polyurethane-based finishing and polishing disks coated with aluminum oxide particles. ${ }^{18,19}$

Promising results were obtained with diamond micropolishers with impregnated rubber in various shapes: Disks, points, and cups. ${ }^{9}$ These are known as one-step polishing systems since contouring, finishing, and polishing can be completed using a single instrument to achieve a smooth surface in a minimal amount of time. $^{20,21}$ Therefore, the aim of this study was to evaluate the surface roughness and microhardness of two types of composites polished with two different types of polishing systems.

\section{MATERIALS AND METHODS}

\section{Preparation of the Specimens}

Two types of composite resins were used in the study (Tables 1 and 2). About 30 specimens with $8 \mathrm{~mm}$ diameter and $2 \mathrm{~mm}$ in thickness were fabricated from each composite resin. A Teflon mold was used for fabrication of the disks. The molds were filled with the composite resin. A Mylar strip and a glass slide were positioned on the strip, and a load of 500g was applied for 30 seconds, followed by light-curing using a light-cure unit positioned in direct contact with the Mylar strip. The cured samples were then stored in dark and 100\% humid environment at $37^{\circ} \mathrm{C}$ for 24 hours prior to finishing.

\section{Polishing Procedures}

One operator performed all the procedures. Both surfaces of the disks were used so as to have a total of 60 tested surfaces for each composite material. The specimens of each material were divided into three groups $(n=20)$. The control group received no finishing or polishing treatment. The other two groups were wet-finished with 600grit silicon carbide abrasive papers on a rotary polisher (Buehler, Metaserv, Buehler, Germany) for 30 seconds to obtain a baseline before using the polishing systems. The first group specimens were polished with diamond micropolisher $\left(\right.$ PoGo $^{\circledR}$ ) disks under dry conditions with light hand pressure using a planar motion for 30 seconds at 15,000 rpm using a slow-speed handpiece. The second set of specimens was polished with Sof-Lex ${ }^{\mathrm{TM}}$ system. The specimens were sequentially polished with medium, fine, and superfine aluminum oxide-impregnated disks (Sof-Lex) under dry conditions for 30 seconds. The disks were thoroughly rinsed with water for 10 seconds to remove debris, air-dried for 5 seconds, and then polished with another disk of lower grit for the same period of time until final polishing. A slight pressure was applied using a constant moving repetitive stroking action in one direction so as to prevent heat buildup or formation of surface grooves. Following polishing, the specimens were ultrasonicated in a water bath for 5 minutes to remove any remaining debris. All specimens were stored in 100\% humid environment at $37^{\circ} \mathrm{C}$ for 24 hours prior to measuring their surface roughness.

\section{Surface Roughness}

The surface roughness was measured three times for each specimen using a surface profilometer (Perthometer M2;

Table 1: Characteristics of the composite restorative materials tested

\begin{tabular}{|c|c|c|}
\hline Product & Type & Composition \\
\hline \multirow[t]{4}{*}{ Filtek $^{\text {TM }}$ Z350 XT (3M ESPE, St. Paul, MN, USA) } & Nanofilled composite & Matrix: Bis-GMA, UDMA, Bis-EMA, TEGDMA \\
\hline & & Filler: zirconia/silica \\
\hline & & Nanofillers of silicon $(5-75 \mathrm{~nm})$ \\
\hline & & $\begin{array}{l}\text { Zircon/silicon nanoclusters }(0.6-1.4 \mu \mathrm{m}) \text { nanofiller } \\
78.5 \% \mathrm{wt}, 59.5 \% \text { vol }\end{array}$ \\
\hline \multirow[t]{2}{*}{ Ceram- $X^{\circledR}$ (Dentsply, DeTrey, Konstanz, Germany) } & Nanohybrid composite & $\begin{array}{l}\text { Ultraviolet stabilizer, camphorquinone, ethyl } 4 \\
\text { (dimethylamino) benzoate, iron dioxide, pigments, } \\
\text { aluminum sulfosilicate pigments }\end{array}$ \\
\hline & & Filler: Barium-aluminum-borosilicate glass \\
\hline
\end{tabular}

Bis-GMA: Bisphenol A diglycidildimethacrylate; UDMA: Urethane dimethacrylate; EMA: ethylmethacrylate; TEGDMA: triethylene glycol dimethacrylate

Table 2: The polishing systems used in the study

\begin{tabular}{lll}
\hline Material & Manufacturer & Composition \\
\hline Sof-Lex ${ }^{\mathrm{TM}}$ disks & $3 \mathrm{M}$ ESPE, St. Paul, MN, USA & $\mathrm{Al}_{2} \mathrm{O}_{3}$ flexible disks \\
PoGo ${ }^{\circledR}$ polishers & Dentsply Caulk, Milford, DE, USA & $\begin{array}{l}\text { Cured composite of urethane dimethacrylate, fine diamond powder, } \\
\text { silicon dioxide } 7 \mu \mathrm{m}, \mathrm{Al}_{2} \mathrm{O}_{3}\end{array}$ \\
\hline
\end{tabular}


Impact of Polishing Systems on the Surface Roughness and Microhardness of Nanocomposites

Mahr GmbH, Göttingen, Germany). For each surface, Ra readings were taken three times, utilizing a stylus speed of $0.1 \mathrm{~mm} /$ second. The mean Ra values of the three readings of each surface were calculated and recorded as Ra of the specimen.

\section{Microhardness Test}

The microhardness was determined using a Vickers hardness test (Micromet 5114; Buehler, Lake Bluff, Illinois, USA). Measurements were performed on samples with $200 \mathrm{~g}$ load for 15 seconds and this measurement was repeated in three different regions of each sample. The mean microhardness was calculated using the values of the three indentations and recorded as the Vickers hardness value of the sample.

\section{Statistical Analysis}

The obtained values for the surface roughness and microhardness were statistically analyzed. The Ra values and the surface hardness were compared between the control and the two polishing systems using analysis of variance at a $95 \%$ confidence interval. To determine the significant differences, multiple comparisons with Bonferroni's correction were performed with the probability set to a 0.05 for statistical significance. All analyses were performed using the InStat ${ }^{\circledR}$ statistical package (InStat, San Diego, CA).

\section{RESULTS}

The surface roughness after the application of PoGo and Filtek polishing systems is listed in Table 3 and Graph 1. The PoGo polishing system showed minimum surface roughness with both composite resins used. There was no significant difference between the control group (Mylar Strips) and the PoGo system. The mean surface roughness

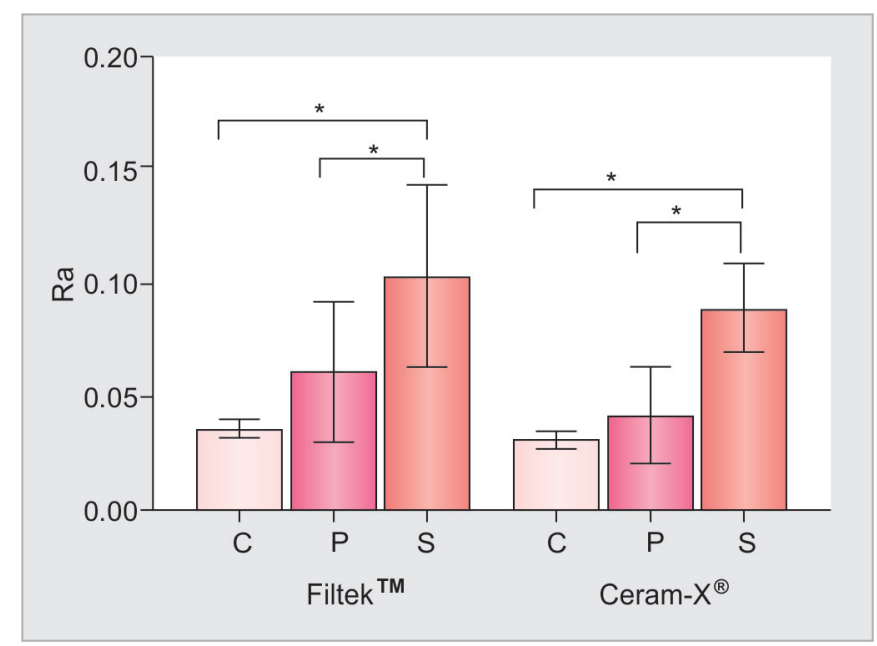

Graph 1: Roughness (Ra) of the control and polished groups (C, control; P, PoGo; S, Sof-Lex)
Table 3: Surface roughness (Ra) and microhardness (VHN) of the composite resins

\begin{tabular}{|c|c|c|c|c|c|}
\hline \multirow[b]{2}{*}{ Composite } & \multirow{2}{*}{$\begin{array}{l}\text { Polishing } \\
\text { system }\end{array}$} & \multicolumn{2}{|c|}{$\begin{array}{l}\text { Surface roughness } \\
\text { Ra values }(\mu \mathrm{m})\end{array}$} & \multicolumn{2}{|c|}{$\begin{array}{l}\text { Microhardness } \\
\text { VHN }\end{array}$} \\
\hline & & Mean & $S D$ & Mean & $S D$ \\
\hline \multirow{3}{*}{ Filtek $^{\mathrm{TM}}$} & Control & 0.036 & 0.004 & 61.087 & 2.301 \\
\hline & PoGo & 0.061 & 0.031 & 62.245 & 2.806 \\
\hline & Sof-Lex & 0.103 & 0.040 & 63.174 & 2.402 \\
\hline \multirow{3}{*}{ Ceram- $X^{\circledR}$} & Control & 0.031 & 0.004 & 65.152 & 3.079 \\
\hline & PoGo & 0.042 & 0.021 & 65.208 & 3.228 \\
\hline & Sof-Lex & 0.089 & 0.020 & 66.507 & 3.471 \\
\hline
\end{tabular}

VHN: Vickers hardness number; SD: Standard deviation

for the Sof-Lex showed significantly higher $(\mathrm{p}<0.01)$ roughness $(0.10 \pm 0.04)$ for the Filtek Composite resin in comparison with the control system and PoGo system (Graph 1). Similar observations were found with Ceram-X composite resin. The roughness values were $0.10 \pm 0.04$ for the Soflex group compared with $0.04 \pm 0.02$ for the PoGo group. It was found to be statistically significant $(p<0.01)$ in comparison with the control group and the PoGo System.

The microhardness showed relatively lower values after application of the polishing system. There was no significant reduction in hardness compared with the control group in both composite resins. The values are depicted in Table 3 and Graph 2.

\section{DISCUSSION}

Proper finishing and polishing are important steps to enhance the esthetics and long-lasting quality of resin composite restorations. The surface roughness of the restorations can influence dental biofilm retention, staining, gingival inflammation, and secondary caries, thus affecting the clinical performance of restorations. ${ }^{22,23}$ Composite resin restorations have evolved rapidly over the past decade. Advances, such as nano and hybrid

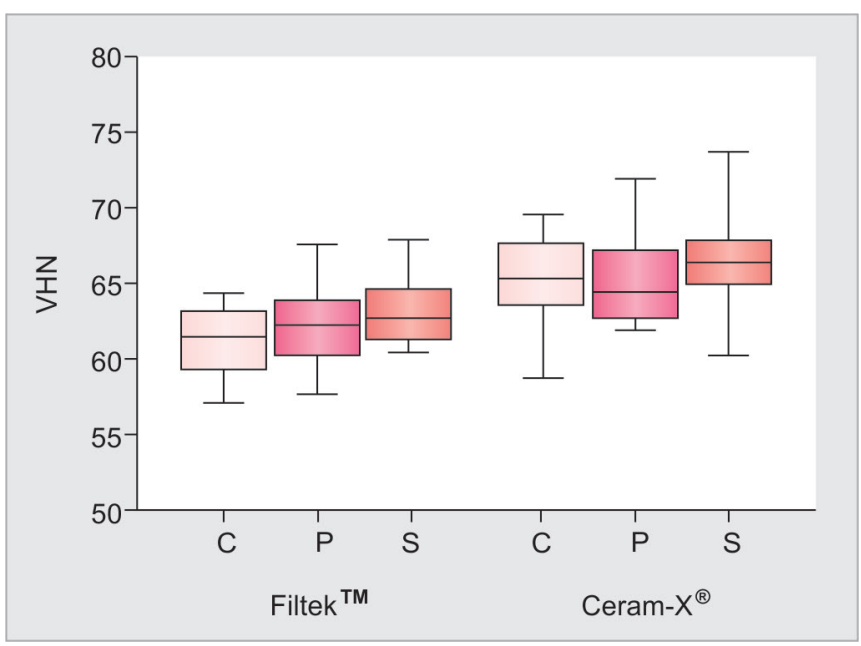

Graph 2: Surface hardness (Vickers hardness number) of the control and polished groups (C, control; P, PoGo; S, Sof-Lex) 
composite materials, new etching and bonding materials, fast curing methods, and new finishing and polishing materials and techniques have contributed to high-quality composite restorations. ${ }^{24}$

Several polishing systems are available as stand-alone products as kits containing disks, cups, and points and are finer than finishing disks, cups, and points. ${ }^{25}$ The effectiveness of the polishing system depends on the hardness of the cutting particles and materials, such as aluminum oxide $\left(\mathrm{Al}_{2} \mathrm{O}_{3}\right)$, which provide less roughness on surfaces of composites. The production of a smooth surface may also depend on the ability to cut the filler particles and organic matrix. ${ }^{26}$ Some of the available polishing systems are PoGo ${ }^{\circledR}$ One-step Diamond Micro-Polishers (DENTSPLY Caulk); Sof-Lex ${ }^{\circledR}$ Superfine polishing disks (3M Espe), which contains aluminum oxide; Astropol ${ }^{\circledR}$ (Ivoclar); Identoflex (Centrix); and Jiffy Polishers $^{\circledR}$ (Ultradent).

Nanocomposites have the strength of hybrid composites combined with the esthetic characteristics of microfill composites. They have several advantages including reduced polymerization shrinkage, improved optical characteristics, better gloss retention, and wear resistance due to the polymer matrix and filler particle size and increased filler loading. ${ }^{27,28}$ The control group which is untreated and covered with Mylar strips showed better surface smoothness compared with the polished surfaces. This is in accordance with the findings of earlier studies. ${ }^{29,30}$ However, leaving resin surfaces as such is unacceptable due to the presence of the oxygen-inhibited layer, which will result in high water absorption and discoloration. ${ }^{11,16,20,31}$ The surface roughness of composite resins is influenced by the size, hardness, and amount of filler material. ${ }^{32}$ The surface roughness varied with the polishing systems and the type of composite used. The diamond micropolisher disk, named $\mathrm{PoGo}^{\circledR}$, has been developed as a one-step polishing system. ${ }^{15}$ The PoGo ${ }^{\circledR}$ polishing system showed the smoothest surfaces for both composite resins used. These results are in agreement with earlier studies. ${ }^{11,30}$ In the present study, Sof-Lex showed significantly higher roughness values than the PoGo system. This could be attributed to the composition of the material and the type of filler particles. This observation is in agreement with earlier studies. 9,32

The surface roughness and hardness of the composites are directly associated with filler particles, size of filler particles, percentage of filler loading in the organic matrix, and ability of polishing system to wear the surface of restoration. ${ }^{33}$ Although the surface obtained with Mylar strip is perfectly smooth, studies have shown that the outermost layer, which is rich with resin organic binder, has to be removed to produce a harder, wear resistant and esthetically stable surface. ${ }^{11,16,20,31,34}$
Though both polishing systems tested in this study showed similar results in two composite systems, Ceram-X showed relatively lower values. The flexibility, hardness, and the granulations of the polishing system can influence the surface roughness of restorative materials. The discrepancy between the size of abrasive particles present in the abrasive disks and abraded material should be minimal to reduce the creation of scratches or roughs on the polished surface. ${ }^{35}$ The hardness of the composite materials depends on the amount of filler, composition, resin type, and the depth of polymerization. The overall hardness of the material is influenced by the monomers that do not participate in the curing process, which lower the hardness. The increased amount of inorganic filler also contributes to the hardness of the composite. ${ }^{35,36}$ In the present study, it was found that the control group finished with Mylar strip showed lower microhardness values than the groups that have undergone polishing. However, it was not statistically significant. Few earlier studies reported similar observation with significantly lower microhardness compared with the polished surface. $^{32,35}$

\section{CONCLUSION}

Within the limitations of the study, it can be concluded that finishing and polishing with PoGo ${ }^{\circledR}$ system produced smoother surfaces in comparison with Sof-Lex polishing in both type of composites studied. The surface hardness of the composite resin has negligible effect on the polishing system used.

\section{REFERENCES}

1. Patel SB, Gordan VV, Barrett AA, Shen C. The effect of surface finishing and storage solutions on the color stability of resinbased composites. J Am Dent Assoc 2004 May;135(5):587-594.

2. Lu H, Roeder LB, Lei L, Powers JM. Effect of surface roughness on stain resistance of dental resin composites. J Esthet Restor Dent 2005 Mar;17(2):102-108.

3. Morgan M. Finishing and polishing of direct posterior resin restorations. Pract Proced Aesthet Dent 2004 Apr;16(3):211-217.

4. Yap AU, Lye KW, Sau CW. Effects of aging on repair of resin-modified glass-ionomer cements. J Oral Rehabil 2000 May;27(5):422-427.

5. Ryba TM, Dunn WJ, Murchison DF. Surface roughness of various packable composites. Oper Dent 2002 May-Jun; 27(3):243-247.

6. Hooshmand T, Tabari N, Keshvad A. Marginal leakage and microhardness evaluation of low-shrinkage resin-based restorative materials. Gen Dent 2013 Jan-Feb;61(1):46-50.

7. Mitra SB, Wu D, Holmes BN. An application of nanotechnology in advanced dental materials. J Am Dent Assoc 2003 Oct;134(10):1382-1390.

8. Beun S, Glorieux T, Devaux J, Vreven J, Leloup G. Characterization of nanofilled compared to universal and microfilled composites. Dent Mater 2007 Jan;23(1):51-59. 
9. Ozel E, Korkmaz Y, Attar N, Karabulut E. Effect of one-step polishing systems on surface roughness of different flowable restorative materials. Dent Mater J 2008 Nov;27(6):755-764.

10. Watanabe T,MiyazakiM,TakamizawaT,Kurokawa H,RikutaA, Ando S. Influence of polishing duration on surface roughness of resin composites. J Oral Sci 2005 Mar;47(1):21-25.

11. Ergücü $Z$, Türkün LS. Surface roughness of novel resin composites polished with one-step systems. Oper Dent 2007 Mar-Apr;32(2):185-192.

12. Jung M, Sehr K, Klimek J. Surface texture of four nanofilled and one hybrid composite after finishing. Oper Dent 2007 Jan-Feb;32(1):45-52.

13. Scheibe KG, Almeida KG, Medeiros IS, Costa JF, Alves CM. Effect of different polishing systems on the surface roughness of microhybrid composites. J Appl Oral Sci 2009 Jan-Feb; 17(1):21-26

14. Janus J, Fauxpoint G, Arntz Y, Pelletier H, Etienne O. Surface roughness and morphology of three nanocomposites after two different polishing treatments by a multitechnique approach. Dent Mater 2010 May;26(5):416-425.

15. Bashetty K, Joshi S. The effect of one-step and multi-step polishing systems on surface texture of two different resin composites. J Conserv Dent 2010 Apr;13(1):34-38.

16. Joniot SB, Grégoire GL, Auther AM, Roques YM. Threedimensional optical profilometry analysis of surface states obtained after finishing sequences for three composite resins. Oper Dent 2000 Jul-Aug;25(4):311-315.

17. Jones CS, Billington RW, Pearson GJ. The in vivo perception of roughness of restorations. Br Dent J 2004 Jan;196(1): $42-45$.

18. Attar N. The effect of finishing and polishing procedures on the surface roughness of composite resin materials. J Contemp Dent Pract 2007 Jan;8(1):27-35.

19. Patel B, Chhabra N, Jain D. Effect of different polishing systems on the surface roughness of nano-hybrid composites. J Conserv Dent 2016 Jan;19(1):37-40.

20. Türkün LS, Türkün M. The effect of one-step polishing system on the surface roughness of three esthetic resin composite materials. Oper Dent 2004 Mar-Apr;29(2):203-211.

21. Yap AU, Yap SH, Teo CK, Ng JJ. Finishing/polishing of composite and compomer restoratives: effectiveness of one-step systems. Oper Dent 2004 May-Jun;29(3):275-279.

22. Heintze SD, Forjanic M, Ohmiti K, Rousson V. Surface deterioration of dental materials after simulated toothbrushing in relation to brushing time and load. Dent Mater 2010 Apr;26(4): 306-319.
23. Vrochari AD, Petropoulou A, Chronopoulos V, Polydorou O, Massey W, Hellwig E. Evaluation of surface roughness of ceramic and resin composite material used for conservative indirect restorations, after repolishing by intraoral means. J Prosthodont 2015 Oct;26(4):296-301.

24. Small BW. Direct resin composites for 2002 and beyond. Gen Dent 2002 Jan-Feb;50(1):30-33.

25. Koupis NS, Marks LA, Verbeeck RM, Martens LC. Review: finishing and polishing procedures of (resin-modified) glass ionomers and compomers in paediatric dentistry. Eur Arch Paediatr Dent 2007 Mar;8(1):22-28.

26. Barcellos DC, Borges ALS, Borges AB, Pleffken PR, Rode SM. Surface roughness of indirect composites using different polishing systems. Braz Dent Sci 2013Oct-Dec;16(4):77-83.

27. Sapra V, Taneja S, Kumar M. Surface geometry of various nanofiller composites using different polishing systems: a comparative study. J Conserv Dent 2013 Nov-Dec;16(6):559-563.

28. Jung M, Bruegger $H$, Klimek J. Surface geometry of three packable and one hybrid composite after polishing. Oper Dent 2003 Nov-Dec;28(6):816-824.

29. Barbosa SH, Zanata RL, Navarro MF, Nunes OB. Effect of different finishing and polishing techniques on the surface roughness of microfilled, hybrid and packable composite resins. Braz Dent J 2005 Aug;16(1):39-44.

30. Ereifej NS, Oweis YG, Eliades G. The effect of polishing technique on 3-D surface roughness and gloss of dental restorative resin composites. Oper Dent 2013 Jan-Feb;38(1):E1-E12.

31. Heath JR, Jordan JH, Watts DC. The effect of time of trimming on the surface finish of anterior composite resins. J Oral Rehabil 1993 Jan;20(1):45-52.

32. Korkmaz Y, Ozel E, Attar N, Aksoy G. The influence of one-step polishing systems on the surface roughness and microhardness of nanocomposites. Oper Dent 2008 Jan-Feb;33(1):44-50.

33. Yap AU, Wong ML, Lim AC. The effect of polishing systems on microleakage of tooth-coloured restoratives. Part 2: composite and polyacid-modified composite resins. J Oral Rehabil 2000 Mar;27(3):205-210.

34. Lutz F, Setcos JC, Phillips RW. New finishing instruments for composite resins. J Am Dent Assoc 1983 Oct;107(4):575-580.

35. Erdemir U, Sancakli HS, Yildiz E. The effect of one-step and multi-step polishing systems on the surface roughness and microhardness of novel resin composites. Eur J Dent 2012 Apr;6(2):198-205.

36. Chung KH. The relationship between composition and properties of posterior resin composites. J Dent Res 1990 Mar;69(3):852-856. 